DOI 10.37882/2223-2982.2020.09.37

\title{
ФОРМЫ ПРЕФИКСАЛЬНЫХ ПРОИЗВОДНЫХ СУЩЕСТВИТЕЛЬНЫХ В ПЕЙОРАТИВНЫХ ПРОЦЕССАХ В РУССКОМ, НЕМЕЦКОМ И ТАЙСКОМ ЯЗЫКАХ (СОПОСТАВИТЕЛЬНЫЙ АСПЕКТ)
}

\section{FORMS OF PREFIXAL DERIVATIVES OF NOUN IN PEJORATIVE SENSE DEVELOPMENT IN RUSSIAN, GERMAN AND THAI LANGUAGES (COMPARATIVE ASPECT)}

\section{K. Chusuwan}

Summary: This article discusses the processes of formation of prefixal derivatives of nouns that convey a pejorative meaning in languages with different language structures, namely in Russian, German and Thai. Particular attention is paid to a comparative analysis of the form of nouns, derived by prefixing, the values of word formation formants, such as prefixes, semi-prefixes, as well as their correspondences and inconsistencies according to established models, and similar and distinctive features in the analyzed languages are indicated.

The relevance of the study is due to the need to determine the forms of nouns that are derived in a prefixal method and transmitting a pejorative meaning in the form of established models in languages with different language structures. The subject of the research is the prefixal wordformation processes with pejorative meaning. The forms of derivatives in Russian, German and Thai are determined by modeling.

As an object of selective analysis and material, explanatory dictionaries and word-formation explanatory dictionaries are used. The scientific novelty of the proposed study is seen in a comparative analysis of the features of prefixation, conveying the pejorative meaning in languages with different language structures, as well as in the analysis of structures and the establishment of models of derivatives.

Keywords: prefixation, pejoration, pejorative semi-prefix, shade of neglect, proper name.
$\mathrm{T}$ ермин «пейорация» относится к словам или грамматическим формам, имеющим отрицательный оттенок или передающим негативное мнение о ком-то или о чем-либо, неуважение к кому-либо или чему-либо. Пейорация используется в целях выражения критики, враждебности и пренебрежения или того, что считается уничижительным, отрицательным в некоторых социальных или этнических группах, однако языковая единица, которая изначально обладала отрицательным значением, в некоторых контекстах может восприниматься в неотрицательном (не пейоративном) смысле (или наоборот) [10].
Чусуван Критсада

Аспирант, Нижегородский государственный лингвистический университет им. Н.А. Добролюбова,

Нижний Новгород

nunu_kritsad@mail.ru

Аннотация: В данной статье рассматриваются процессы образования префиксальных производных существительных, передающих пейоративное значение, в разноструктурных языках, а именно в русском, немецком и тайском языках. Особое внимание уделяется сравнительно-сопоставительному анализу форм существительных, образованных путем префиксации, значений словообразовательных формантов, таких как префиксы, префиксоиды, а также анализу их соответствий и несоответствий по установленным моделям, причем указываются сходные и отличительные черты в проанализированных языках. Актуальность исследования обусловлена необходимостью определить формы существительных, образованных префиксальным способом и передающих пейоративное значение, в виде установления моделей в разноструктурных языках. Предметом исследования являются процессы префиксального словообразования с пейоративным значением. Формы производных существительных в русском, немецком и тайском языках определяются посредством моделирования.

В качестве объекта выборочного анализа и материала используются толковые словари и словообразовательные толковые словари. Научная новизна предлагаемого исследования видится в сравнительно-сопоставительном анализе особенностей префиксации, передающей пейоративное значение в разноструктурных языках, а также в анализе структур и установленных моделей производных существительных.

Ключевые слова: префиксация, пейорация, пейоративный префиксоид, оттенок пренебрежения, имя собственное.

В лингвистике, особенно в семантике, пейорацией называется процесс, при котором лингвистическая единица «неявно обесценивает» свое значение[9]. Следовательно, пейорация не является грамматической частью слова, но указывает на намерение говорящего оценить что-то или кого-то заведомо низко с помощью подобных языковых единиц. В области словообразования проблема пейорации связана с выбором определенных префиксов и суффиксов [9].

Проблема образования существительных путем префиксации с пейоративным значением в разноструктур- 
ных языках - находится в центре нашего научного интереса и будет рассмотрена в данной статье.

\section{1. Префиксальный способ образования сушествительных с пейоративным значением в русском языке}

Пейорация, или негативная оценка, может оформиться у слова, обозначающего исходно очень негативные явления. В русском языке к словам этой группы относятся в первую очередь бранные слова (ненормативная лексика) и выражения. Помимо этого имена существительные с пейоративным значением образуются посредством префиксации.

Исконно русский префиксоид лже- образует производные слова с общим словообразоватнльным значением 'ненастоящесть, ложность' по модели: лже- + существительное, например: лже- + царь = лжецарь; лже- + судья = лжесудья; лже- + научность = лженаучность; лже- + исскуство = лжеисскуство; лже- + предсказание = лжепредсказание.

Префиксоид греко-латинского происхождения псевдо- образует производные слова с общим словообразоватнльным значением 'ненастоящесть, ложность', 'временная или замещающая формация, аналогичная чему-либо'[11], по модели: псевдо- + существительное, например: псевдо- + друг = псевдо|друг; псевдо- + ученый = псевдо ученый; псевдо- + гуманист = псевдо|гуманист.

Использование префиксоидов лже- и псевдо-, однако, относится к разным сферам жизни общества и наук, например: в области профессии и деятельности, в области исскуства, литературы, в области естественных наук [1, с. 19][5]. Однако, по нашему мнению, хотя значение 'ненастоящесть, ложность' может включаться в совокупность пейорации, но префиксальные имена существительные, образованные с помощью этого префиксоида в некоторых областях, где они используются как специфицические термины, рассматриваются как префиксальные производные существительные без пейоративного значения, например: лже- + акация = лже|акация 'робииния лжеакация - быстрорастущее лесообразующее засухоустойчивое дерево семейства бобовых (белая акация)'; лже- + лопатонос = лже|лопатонос 'род рыб семейства осетровых'; псевдо- + бутилен = псевдо|бутилен '(2-бутен, b-бутилен) - представитель ряда олефинов, при $+18^{\circ} \mathrm{C}$ представляет собой газообразное вещество, без цвета и запаха'. Прежде упомянутые префиксальные производные существительные не имеют эмоционально-экспрессивной негативной окраски.

Будучи синонимичным префиксоиду лже-, префиксоид псевдо- отличается от префиксоида лже- оттенками значений. Лже- вследствие наличия семы «ложный», «выражает определенное «самозванство», активность признака, т. е. Y выдает себя за X, а псевдо- чаще выражает

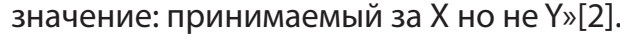

По итогам нашего наблюдения за процессом префиксации с пейоративным значением в русском языке отмечаем, что префиксоиды лже- и псевдо-, используемые в русском словообразовании, являются слабыми пейоративными префиксоидами.

Следует, однако, отметить, что добавление еще увеличительного или аугментативного префиксоида к имеющимся префиксальным производным существительным с пейоративным значением как образование в виде сложной формы или множественной префиксации позволяет нам усиливать пейоративное значение по модели: увеличительный или аугментативный префиксоид + (дефис) + [пейоративный префиксоид + существительное], например: супер- + [псевдо- + голограммы] = супер|-псевдо|голограммы. Такое образование возможно, но является индивидуально-авторским новообразованием, которое можно определить как потенциальный или окказиональный тип.

Таким образом, для префиксальных производных существительных, передающих пейоративное значение, в русском языке можно выделить следующие структурные модели:

Модель $1_{\text {русский язык }}$ Пейоративный префиксоид + лексема $\rightarrow$ префиксальное производное существительное с пейоративным значением, например: лже- + друг = лже|друг; псевдо- + гуманист = псевдо|гуманист.

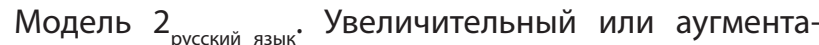
тивный префиксоид + (дефис) + [пейоративный префиксоид + лексема] $\rightarrow$ префиксальное производное существительное с увеличением пейоративного значения, например: супер- + [nсевдо- + голограммы] = супер $\mid$ псевдо|голограммы.

\section{2. Префиксальный способ образования сушествительных с пейоративным значением в немешком языке}

В современном немецком языке, как и в других языках, выделяются две группы пейоративной лексики: структурно-производная пейоративная лексика и семантически производные лексемы, такие как Arschloch 'дурак, козер', Waschlappen 'слютяй, размозня'. В данном разделе речь пойдет о пейорации с точки зрения теории словообразования.

Продуктивный префикс Erz- придает существительным усилительное значение и может использоваться для образования слов, передающих негативную характеристику лица, например: Erz- + Feind 'враг' = Erz|feind 'заклятый враг'; Erz- + Schurke 'негодяй' = Erzlschurke 'отъявленный негодяй'. Однако префикс Erz- может передавать также значение более высокого ранга обозначаемого лица, и в этом случае образуемое существительное 
не будет иметь пейоративного оттенка, например: Erz- + Bischof 'enuckon' = Erz|bischof 'apxuenucкon'; Erz- + Mutter 'мать' = Erz|mutter 'nраматерь', 'пустая порода, в которой заключается руда (мутационное значение)' [7, S. 364] [3, с. 145]

В немецком языке есть еще одно существительное, образованное по той же модели, но с префиксом Unter'nод-', который обычно выражает значение низшего звания или должности при основах существительных, обозначающих лиц по их званию, должности или деятельности [3 с. 436]. В сочетании с основой Mensch 'человек' префикс Unter- 'nод-' передает негативную оценочность: Unter|mensch 'недочеловек'. Данная производная лексема по сути представляет собой мотивированную лакуну - лакуну, которая объясняется отсутствием соответствующего предмета или явления в национальной культуре. Печально известный термин Unter|mensch 'недочеловек' использовали нацисты для обозначения людей неарийского происхождения, «низших людей», часто называемых «массами с Востока», то есть евреев, цыган и славян - в основном поляков, сербов, а позже и русских [8].

Итак, для префиксальных производных существительных, передающих пейоративное значение, можно выделить следующие структурные модели:

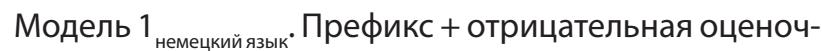
ная лексема $\rightarrow$ производное существительное с пейоративным значением, например: Erz- + Schurke 'негодяй' = Erz|schurke 'отъявленный негодяй'.

Модель $2_{\text {немецкийязык }}$ Префикс статуса, степени и меры + нейтральная лексема $\rightarrow$ производное существительное с пейоративным значением как мутационным значением, например: Unter- + Mensch 'человек' = Untermensch 'недо|человек'.

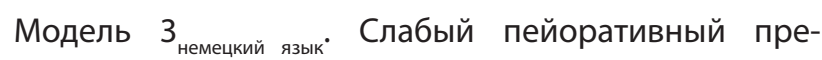
фиксоид + нейтральная лексема $\rightarrow$ производное существительное с слабым пейоративным значением, например: Pseudo- 'nсевдо-' + Wissenschaft 'наука' = Pseudo|wissenschaft 'nсевдонаука'; Möchtegern-' подражатель' + Künstler'художник' = Möchtegern|künstler 'художник-подражатель'.

Словообразование с помощью префиксоидов с пейоративным значением может осуществляться по двум моделям:

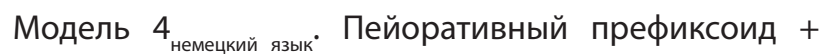
нейтральная лексема $\rightarrow$ производное существительное с пейоративным значением. Функция префиксоидов - формирование новых лексем с пейоративным значением, например: Mist- + Stück 'eдиница' = Mist|stück 'отвратительный mun'; Huren- + Kind 'ребенок' = Huren|kind 'вневрачный ребенок'; Scheiß- + Waffe 'оружие' = Scheiß|waffe 'чертово оружие'.

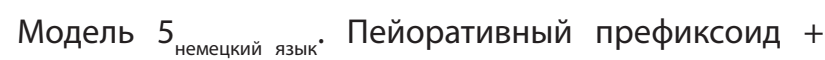
отрицательная оценочная лексема $\rightarrow$ производное существительное с пейоративным значением. Пейоративный префиксоид в этом случае усиливает значение пейоративной лексемы, например: Sau- + Idiot 'uдuom' = Saulidiot; Scheiß- + Kanacke 'темнокожий иностранеи' = Scheiß|kanacke.

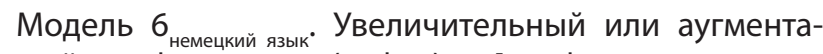
тивный префиксоид + (дефис) + [префиксальное производное существительное с пейоративным значением, образованное по модели $3,4,5] \rightarrow$ производное существительное с увеличением пейоративного значения (образование множества окказиональных производных/ возможный вариант), например: Super- + [Scheiß- + Waffe 'оружие'] = Super|-Scheiß|waffe 'cynер чертово оружие'. (3); Super- + [Sau- + Idiot $]=$ Super|-Sau|idiot (4);

Модель 7 немецкий язык. Пейоративный префиксоид + (дефис) + [префиксальное производное существительное с пейоративным значением, образованное по моделям 1, 2 ] $\rightarrow$ производное существительное с увеличением пейоративного значения (образование множества окказиональных производных/ возможный вариант), например: Scheiß- + [Pseudo-'nсевдо-' + Entschuldigung 'извиненuе'] = Scheiß|-Pseudo|-Entschuldigung.

\section{3. Префиксальный способ образования сушествительных с пейоративным значением в тайском языке}

Тайский язык, с точки зрения лингвистической типологии, является аналитическим языком, если учитывать передачу синтаксических отношений между словами в предложении посредством вспомогательных слов (частиц, предлогов и т.д.) и порядка слов. Его также можно считать изолирующим языком, принимая во внимание низкий коэффициент соотношения количества морфем и слов и отсутствие флективной морфологии [6].

В тайском языке отсутствуют исконно тайские префиксы и суффиксы, но обнаруживается ряд префиксоидов и суффиксоидов, аналогичных по функции префиксам, префиксоидам, суффиксам и суффиксоидам в других языках. Для образования существительных с пейоративным значением используются только префиксоиды по модели:

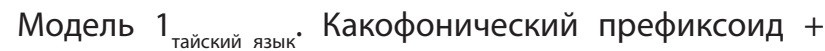
нейтральная лексема (чаще всего название животного, имя собственное / имена людей) $\rightarrow$ производное существительное с пейоративным значением, например: อี- [?i:] + สุพร [sù? pho:n] 'Супхорн (имя собственное)' = อี|สุพร [?i:| sù? pho:n] - выражение недовольства по отношению к лицу, которого зовут สุพร [sù? pho:n]; ไอ้- [?âj] + แดง

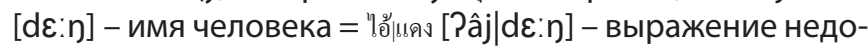
вольства по отношению к лицу, которого зовут แดง [dع:n].

Модель $2_{\text {тайский язык }}$ Какофонический префиксоид + от- 
рицательная оценочная лексема ((чаще всего название животного) $\rightarrow$ производное существительное с пейоративным значением, например: อี- [?i:] + แรด [rє̂.t]'носорог' = อี|แรด [?i:| rє̊.t] 'женщины, которые бьют друг друга из-за мужчины'; ไอ้- [?âj] + เปรต [prè:t] 'демон голода в тайской культуре' = ไอ้|เปรต [?âj|prè:t] 'тот, кто ведет себя невежливо или делает что-то очень плохое' - также является междометием, выполняющим функцию очень эмоционального ругательства.

Какофонический префиксоид в тайском языке представляет собой первую часть слова, подчеркивающую негативную оценку. Он неблагозвучен, может участвовать в наименовании лица и является негативно-оценочным междометием в разговорном варианте тайского языка. Какофонические префиксоиды ไอ้- [?âj] и อี- [?i:] широко используются в языке, причем иногда префиксоид ไอ้- [?âj] употребляется при обращении к мужчине, а префиксоид ё- [?і:] - к женщине [4].

Какофонические префиксоиды, однако, не всегда передают пейорацию. Использование производных существительных с данными префиксоидами зависит от контекста, целей коммуникации. Например, образованное с помощью какофонического префиксоида слово ไอ้|แดง [?âj dع:n] используется при обращении к тому, кого

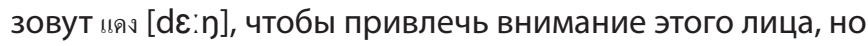
обращение при этом будет невежливым, хотя это производное слово будет нормой для определённого диалекта тайского языка [4]

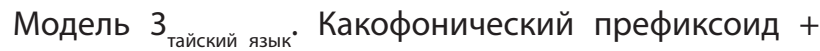
[пейоративный префиксоид + отрицательная оценочная лексема] $\rightarrow$ производное существительное с пейоративным значением, например: ไอ้- [?âj] + [ขै-[khî:]'кал , испражнение - очень негативная оценка' + пลัว [klu:a] 'испугаться' или 'боязливый'] = ไอ้|ขै|กลัว [?âj|khî:|k lu:a] 'очень боязливый (прил.)' или 'тот, кто очень боязлив (сущ., транспозиционное значение)'. Продуктивный пейоративный префиксоид ขै- [khî:] в данном контексте используется для образования имен прилагательных по модели ขै- [khî:] + пейоративная лексема (имя прилагательное или глагол) $\rightarrow$ имя прилагательное с пейоративным значением, например: ขै- [khî:] 'очень негативная оценка' + กลัว [:k lu:a] 'испугаться, боязливый' = ขึ|กลัว [khî:k| lu:a] 'очень боязливый'. Какофонический префиксоид ไอ้- [?âj] соединяется с производным существительным ขै|กลัว [khî:|klu:a], его функция - усиление пейорации и изменение части речи исходного слова - с прилагательного на существительное. Образование с помощью префиксоидов ไอ้- [?âj] в этом контексте осуществляется в сложной форме или в виде множественной префиксации.

\section{4. Соответствия и несоответствия префиксального способа образования сушествительных в пейоративных прочессах в русском, немешком и тайском языках}

Анализ примеров из русского, немецкого и тайского языков подтверждает тот факт, что во всех указанных языках в процессе образования имен существительных с пейоративным значением используется префиксация. Виды способов представлены в таблице.

\begin{tabular}{|c|c|c|c|}
\hline \multirow[t]{2}{*}{ Языки } & \multicolumn{3}{|c|}{$\begin{array}{c}\text { Словообразовательные форманты в процессе } \\
\text { префиксании }\end{array}$} \\
\hline & префиксы & префиксоиды & Смешанный \\
\hline Русский & - & 2 модели & 1 модель \\
\hline Немецкий & 2 модели & 3 модели & 2 модели \\
\hline Тайский & - & 3 модели & - \\
\hline
\end{tabular}

Анализ данных в таблице показывает, что в немецком языке префиксы и префиксоиды используются для образования существительных с пейоративным значением и выделяются семь моделей. Способ образования существительных с помощью префиксов реализуются в немецком языке, а способ образования существительных с помощью префиксоидов оказывается частотным во всех наших проанализированных разноструктурных языках.

Рассмотрев словообразовательные модели в русском и немецком языках, можно сделать вывод о межъязыковом соответствии следующих моделей: Модель $1_{\text {русский язык. }}$ и Модель $3_{\text {немецкий язык, }}$, а также Модель $2_{\text {русский язык. }}$ и Модель $6_{\text {немецкий язык. }}$

По моделям префиксации в тайском языке, несмотря на отуствие полных соответствий в русском и немецком языках, еще могут образоваться разные префиксальные производные существительные с пейоративным значе-

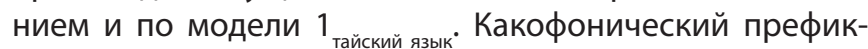
соид является неотъемлемой словообразовательной частью. Но иногда образованное по этой модели слово в тайском языке как бы теряет неблагозвучие и не выражает пейоративное значение, если производное слово соответствует цели говорящего или относится к диалекту тайского языка. В немецком языке в качестве примера мотивированной лакуны с пейоративным мутационным значением может выступать слово Unter|mensch 'недо|человек' как префиксальное имя существительное, образованное с помощью префикса статуса, степени и меры Unter- 'под-'.

Интересным представляется также тот факт, что пейоративный префиксоид в тайском языке ขึ- [khî:] и немецкие префиксоиды Scheiß-, Mist-, Dreck- являются полными эквивалентами при переводе.

Словообразовательные форманты, использованные для образования имен существительных в пейоратив- 
ных процессах, выполняют особые функции. В русском, немецком и тайском языках можно выделить их виды, участвующих в пейоративных процессах.

1. Префиксы с разными значениями, которые не всегда могут придавать слову пейоративную окраску, свойственны немецкому языку и позволяют образовать префиксальные производные существительные с пейоративным значением.

2. Пейоративные префиксоиды - префиксоиды, образующие имена существительные и привносящие в семантику этих существительных элементы отрицательно-оценочного, или пейоративного значения - такие префиксоиды встречаются в русском, немецком и тайском языках.

3. Сами слабые пейоративные префиксоиды, такие как лже-, псевдо-, Pseudo- и др. в русском и немецком языках, по нашему мнению, имеют низкую степень отрицательно-оценочного значения и негативной эмоциональной окраски. Более того, префиксальные производные существительные, образованные с помощью этих префиксоидов, иногда теряют пейоративное значение и употребляются в специфической терминологии.

4. Какофонические префиксоиды - префиксоиды, которые часто используются для образования наименований мужчин и женщин и подчеркивают негативное отношение к ним и негативной эмоциональной окраски. Иногда эти префиксоиды в тайском языке используются как отрицательнооценочное междометие.

5. Префиксальные производные существительные с увеличением пейоративного значения в русском, немецком и тайском языках могут образоваться путем множественной префиксации, в процессе которой увеличительные, пейоративные или какофонические префиксоиды добавляются к имеющимся префиксальным производным существительным с пейоративным значением. Такое образование обычно дает нам потенциальные или окказиональные типы производных слов.

Таким образом, разные префиксы и префиксоиды служат для образования существительных и передают пейоративное значение в разноструктурных языках. С учетом частотности описанных выше типов словообразования и моделей следует отметить, что большая часть префиксов и префиксоидов, которые используются для передачи очень отрицательно-оценочного значения и негативной эмоциональной окраски, являются непродуктивными. Тем не менее, все же необходимо отметить, что в русском языке префиксоиды малопродуктивны, а в тайском языке образование пейоративной лексики с помощью префиксоидов представляется весьма продуктивным способом словообразования.

Итак, результаты сопоставительного анализа пейоративных моделей позволяют сделать вывод о том, что дифференцированный характер префиксации в разноструктурных языках создает возможность для выражения множества смысловых и эмоциональных оттенков, передающих пейоративность. В проанализированных языках обнаруживаются как сходства, так и различия в реализации пейоративных процессов, в которых образуются префиксальные производные существительные.

\section{ЛИТЕРАТУРА}

1. Баранов В.В. История словообразования префиксальных существительных в русском языке XVIII-XX вB. (на материале производных с приставками анти-, контр-, противо-, де-/дез-, дис-, а-, лже-, псевдо-, квази-): автореф. дис. ... кандидата филологических наук: спец. 10.02 .01 - русский язык / В. В. Баранов. - М., 1996. - 22 с.

2. Голанова Е.А. 06 одном типе препозитивных единиц в современном русском языке (на материале имен существительных с префиксами квази-, лже-, псевдо-).//Развитие современного русского языка. 1972. Словообразование. Членимость слова. —М., 1975. — с. 170

3. Зуев А.Н., Молчанова И.Д., Мурясов Р.З. и др. под рук. Степанова М.Д. Словарь словообразовательных элементов немецкого языка. — М.: Русский язык, 1979. - 536 c

4. Морев, Л.Н. Тайско-русский словарь/ Л.Н. Морев. - М.: Советская энциклопедия, 1964. - 985 с.

5. Слова греко-латинского происхождения в русском языке. - М.: Из-во МГпИ им. В.И. Ленина, 1986. — 88 с.

6. Ausbau and Abstand languages». Ccat.sas.upenn.edu. 1995-01-20. Retrieved 2019-07-29.

7. Fleischer,W.Wortbildung der deutschen Gegenwartssprache. Veb Bibliographisches Institut, Leipzig, 1976. — 364 S.

8. Gumkowski, Janusz; Leszczynski, Kazimierz; Robert, Edward (translator) (1961). Hitler's Plans for Eastern Europe. Poland Under Nazi Occupation (First ed.). Polonia Pub. House. p. 219

9. Helmut Rehbock: Pejorativ. In: Helmut Glück (Hrsg.): Metzler Lexikon Sprache. 2., überarbeiteteunderweiterteAuflage, Metzler, Stuttgart/Weimar, 2000. — S. 515

10. Pejorative | Define Pejorative at Dictionary.com». Dictionary.reference.com. Retrieved 2020-04-18.

11. Thillmann S. A linguistic analysis of the word forming element 'pseudo-'English Language and Literature Studies - Linguistics, printed single-sided, grade: 2,3, University of Marburg (Institut für Anglistik und Amerikanistik), Hineinblättern, 2007. 24 pp.

(с) Чусуван Критсада (nunu_kritsad@mail.ru). 